\title{
Brain-derived neurotrophic factor
} serum levels correlate with cognitive performance in Parkinson's disease patients with mild cognitive impairment

\author{
Alberto Costa ${ }^{1,2 *}$, Antonella Peppe ${ }^{2}$, Giovanni Augusto Carlesimo ${ }^{2,3}$, Silvia Zabberoni ${ }^{2}$, \\ Francesco Scalici ${ }^{2}$, Carlo Caltagirone ${ }^{2,3}$ and Francesco Angelucci ${ }^{2}$ \\ Niccolò Cusano University, Rome, Italy, ${ }^{2}$ IRCCS, Fondazione Santa Lucia, Rome, Italy, ${ }^{3}$ Tor Vergata University, Rome, Italy
}

OPEN ACCESS

Edited by:

Benedetto Sacchetti,

University of Turin, Italy

Reviewed by:

Félix Javier Jiménez-Jiménez, Hospital del Sureste, Spain Marco Cambiaghi,

University of Turin, Italy

*Correspondence:

Alberto Costa,

Niccolò Cusano University,

Via Don Carlo Gnocchi 3,

00166-Roma; IRCCS Fondazione

Santa Lucia, Via Ardeatina 306,

00179-Roma, Italy

alberto.costa@unicusano.it;

a.costa@hsantalucia.it

Received: 11 May 2015 Accepted: 31 August 2015 Published: 15 September 2015

Citation:

Costa A, Peppe A, Carlesimo GA, Zabberoni S, Scalici F, Caltagirone $C$ and Angelucci F (2015) Brain-derived

neurotrophic factor serum levels correlate with cognitive performance

in Parkinson's disease patients with mild cognitive impairment.

Front. Behav. Neurosci. 9:253.

doi: 10.3389/fnbeh.2015.00253
Brain-derived neurotrophic factor (BDNF) is a trophic factor regulating cell survival and synaptic plasticity. Recent findings indicate that BDNF could be a potential regulatory factor for cognitive functioning in normal and/or neuropathological conditions. With regard to neurological disorders, recent data suggest that individuals with Parkinson's disease (PD) may be affected by cognitive deficits and that they have altered BDNF production. Therefore, the hypothesis can be advanced that BDNF levels are associated with the cognitive state of these patients. With this in mind, the present study was aimed at exploring the relationship between BDNF serum levels and cognitive functioning in PD patients with mild cognitive impairment (MCl). Thirteen PD patients with $\mathrm{MCl}$ were included in the study. They were administered an extensive neuropsychological test battery that investigated executive, episodic memory, attention, visual-spatial and language domains. A single score was obtained for each cognitive domain by averaging z-scores on tests belonging to that specific domain. BDNF serum levels were measured by enzyme-linked immunoassay (ELISA). Pearson's correlation analyses were performed between BDNF serum levels and cognitive performance. Results showed a significant positive correlation between BDNF serum levels and both attention $(p<0.05)$ and executive $(p<0.05)$ domains. Moreover, in the executive domain we found a significant correlation between BDNF levels and scores on tests assessing working memory and selfmonitoring/inhibition. These preliminary data suggest that BDNF serum levels are associated with cognitive state in PD patients with $\mathrm{MCl}$. Given the role of BDNF in regulating synaptic plasticity, the present findings give further support to the hypothesis that this trophic factor may be a potential biomarker for evaluating cognitive changes in PD and other neurological syndromes associated with cognitive decline.

Keywords: BDNF, Parkinson's disease, cognitive functions, mild cognitive impairment, neuropsychological deficits 


\section{Introduction}

Brain-derived neurotrophic factor (BDNF) belongs to the family of neurotrophins that regulate the survival and functioning of neurons in the central nervous system (Baydyuk and Xu, 2014). BDNF was originally described as a trophic factor for dopaminergic neurons of the substantia nigra (Hyman et al., 1991). However, successive studies found that its action on neurons is not only trophic but involves the regulation of synaptic plasticity through the activation of signal transduction pathways that influence the release of neurotransmitters such as glutamate and GABA (Gottmann et al., 2009). These effects on synaptic transmission have been associated with the long-term potentiation that takes place in the hippocampus during learning and memory processes (Leal et al., 2014). Thus, BDNF not only has a trophic action but also the potential to regulate cognitive processes.

In recent years, the latter role of BDNF was confirmed in both animal and human studies. In rodent models, it was shown that knockout of the BDNF gene affects spatial learning and memory (Gorski et al., 2003; Monteggia et al., 2004; Heldt et al., 2007), whereas transgenic overexpression of BDNF in cortical and subcortical (i.e., hippocampus) regions sustains performance (Koponen et al., 2004). Li et al. (2012) also documented that, in cognitively affected rats, BDNF infusion into the nucleus accumbens improved cognition, synaptic plasticity and cell signaling. As for human data, in both healthy individuals (Alfimova et al., 2012) and in persons with psychiatric disturbances (Lu et al., 2012; Tükel et al., 2012), BDNF gene polymorphism (Val66Met) was found to be associated with executive dysfunctions. In a sample of more than 50 healthy young subjects, Koven and Collins (2014) recently documented a significant correlation between (urinary) $\mathrm{BDNF}$ concentration and cognitive performance on tests tapping cognitive flexibility (i.e., Trail Making Test, Design Fluency and Verbal Category Switching). Nonetheless the role of BDNF gene polymorphism in Parkinson's disease (PD) is not well defined and the results are sometimes contradictory. While some authors report an association between gene polymorphism with cognitive impairments in PD patients (Foltynie et al., 2005; Guerini et al., 2009) or with the onset of the disease (Karamohamed et al., 2005), other studies do not show such correlations (Dai et al., 2013; Svetel et al., 2013; Białecka et al., 2014). Many of these studies however are not strictly comparable in term of disease stages and the methodology used to assess cognitive impairments (Alonso-Navarro et al., 2014; Białecka et al., 2014). Thus, the results do not permit definitive conclusions. Larger sample-size and multiethnicity studies with homogeneous PD patients and well-matched controls are needed in the future study.

Above data indicate that BDNF could be a potential regulatory factor for cognitive functioning in normal and/or neuropathological conditions. Among the neurological disorders affected by cognitive deficits, PD is interesting because the neuronal pathways affected are involved in some cognitive functions that respond to the action of BDNF (Murer et al., 2001; Guillin et al., 2003). In fact, PD is characterized by dopamine cell loss within the substantia nigra that causes a precocious deafferentation of the nigro-striatal dopamine pathway with later involvement of the meso-cortical and mesolimbic dopamine pathways (Yeterian and Pandya, 1991; Jahanshahi et al., 2010). Thus, in addition to motor disorders PD patients may also present cognitive deficits including mild cognitive impairment (MCI) and dementia (Robbins and Cools, 2014). Typically PD patients with cognitive deficits have a dysexecutive profile that is characterized by poor performance on tests tapping shifting and planning (Cools, 2006; Cools and D'Esposito, 2011; MacDonald and Monchi, 2011), working memory (Cools, 2006; Cools and D'Esposito, 2011) and free recall of studied information (Costa et al., 2014a). As stated before, BDNF is a trophic factor for the dopaminergic neurons of these brain regions. Indeed, many studies have shown that PD patients show decreased BDNF levels in the substantia nigra (pars compacta; Howells et al., 2000) and in serum (Scalzo et al., 2010). Moreover, BDNF serum concentration was associated to the level of dopamine transporter binding in the striatum (Ziebell et al., 2012).

Studies on cerebrospinal fluid (CSF) of PD patients revealed an association between BDNF and cognitive performance (Leverenz et al., 2011) and increased BDNF levels compared with controls (Salehi and Mashayekhi, 2009). Moreover, CSF BDNF levels were found to be reduced in PD patients with major depression (MD) as compared to solely depressed patients after treatment with antidepressants (citalopram; Pålhagen et al., 2010). Despite these studies, the role of CSF BDNF levels as biomarker in PD needs to be replicated according to more strictly diagnostic standardized criteria and in longer follow- up periods (Jiménez-Jiménez et al., 2014).

Altogether these findings suggest that BDNF serum levels may not only be a trait that characterizes dopaminergic dysfunctions in PD patients but could also be a potential biomarker of their cognitive deficits. To test this hypothesis, we performed a pilot study with a groups of individuals with PD and MCI, in which we assessed BDNF serum levels and correlated them with scores obtained on tests measuring episodic memory, language, attention, executive and visual-spatial functions. Since in humans BDNF has been reported to correlate with specific components of the executive domain that are precociously weakened in PD (Koven and Collins, 2014), we expected to find a significant association between BDNF serum levels and PD patients' performance on executive tests.

\section{Materials and Methods}

\section{Patients}

We recruited 13 right-handed subjects with idiopathic PD who gave their written informed consent. The study was approved by Ethics Committee of the Santa Lucia Foundation. The United Kingdom PD Society brain bank criteria were used to diagnosis PD (Hughes et al., 1992).

MCI was diagnosed according to the criteria of Litvan et al. (2012). Accordingly, to be included PD subjects patients have a performance that was $1.5 \mathrm{SD}$ below the average 
performance from the average performance of the normal population on at least one neuropsychological test investigating executive abilities and on another test sensitive to short-term memory/attention, visual-spatial abilities, episodic memory and language (the neuropsychological test battery is described below). The Mini-Mental State Examination (MMSE; Folstein et al., 1975) score had to be $\geq 26$. In order to exclude psychiatric diseases, neurological conditions other than PD, vascular brain damage and major systemic or metabolic pathologies that could influence cognitive performance, we performed neuropsychiatric, neuroradiological (CT or MR) and laboratory examinations.

In order to assess functional abilities in daily living and their relationship with cognitive functioning we administered the Clinical Dementia Rating Scale, the Instrumental Activities of Daily Living scale (Lawton and Brody, 1969) and the Pill questionnaire (Dubois et al., 2007). Severity of depressive and apathy symptoms was also assessed by administering the Beck Depression Inventory (Beck et al., 1961; Visser et al., 2009) and the Apathy Evaluation Scale-self version (Marin et al., 1991; Leentjens et al., 2008), respectively. PD patients were being treated with levodopa and/or dopamine agonists (ropinirole, pramipexole and rotigotine) during examination period. The levodopa equivalent and the clinical and sociodemographic characteristics of the group are reported in Table 1. Twenty healthy controls (HC) were also recruited. Inclusion criteria for $\mathrm{HC}$ were: (i) absence of subjective cognitive deficits and (ii) MMSE score $\geq 26$ (Folstein et al., 1975). Exclusion criteria were: (i) performance 1.5 SD below the normative population on any test of the standardized neuropsychological screening battery; (ii) current or previous neurological or psychiatric disorders, major systemic or metabolic diseases that could potentially affect cognitive functioning; and (iii) taking medications that have an effect on brain functioning. HC were only administered the behavioral tests.

TABLE 1 | Socio-demographic and clinical characteristics of the samples.

\begin{tabular}{|c|c|c|c|c|}
\hline & \multicolumn{2}{|c|}{ Mean (SD) } & \multirow[b]{2}{*}{$F$ values } & \multirow[b]{2}{*}{$p$ values } \\
\hline & PD patients & $\begin{array}{l}\text { Healthy } \\
\text { controls }\end{array}$ & & \\
\hline Age & $68.3(7.8)$ & $66.4(7.4)$ & 0.48 & $>0.40$ \\
\hline $\begin{array}{l}\text { Years of formal } \\
\text { education }\end{array}$ & $11.2(4.9)$ & 12.4 (3.3) & 0.71 & $>0.40$ \\
\hline $\begin{array}{l}\text { Mini mental state } \\
\text { examination }\end{array}$ & 28.1 (1.5) & $29.4(0.7)$ & 12.1 & 0.001 \\
\hline Pill questionnaire & $3.3(0.75)$ & & & \\
\hline ADL & $5.2(1.3)$ & & & \\
\hline IADL & $7.1(1.5)$ & & & \\
\hline $\begin{array}{l}\text { Beck depression } \\
\text { inventory }\end{array}$ & $7.8(5.6)$ & $6.7(5.8)$ & 0.25 & $>0.60$ \\
\hline $\begin{array}{l}\text { Apathy evaluation scale } \\
\text { Disease duration }\end{array}$ & $\begin{array}{r}32.3(6.8) \\
8.8(6.9)\end{array}$ & $28.0(6.1)$ & 3.05 & 0.093 \\
\hline $\begin{array}{l}\text { Daily levodopa } \\
\text { equivalents }\end{array}$ & $695(294)$ & & & \\
\hline UPDRS part-III & $26.5(11.1)$ & & & \\
\hline
\end{tabular}

UPDRS, Unified Parkinson's Disease Rating Scale.
Socio-demographic and clinical characteristics of individuals participating to the study are reported in Table 1.

\section{Neuropsychological Test Battery}

The following neuropsychological tests were administered to subjects according to the domain they assess: (a) Episodic memory: Immediate and Delayed Recall of a 15-Word List (Carlesimo et al., 1996); Prose Recall (Carlesimo et al., 2002); Immediate and delayed reproduction of Rey's Figure (Carlesimo et al., 2002); (b) Attention and short-term memory: Digit Span and Corsi Block Tapping test Forward and Backward (Monaco et al., 2013); Trail Making Test -Part A (Giovagnoli et al., 1996); (c) Executive functions: Phonological Word Fluency (Carlesimo et al., 1996); Modified Card Sorting test (MCST; Nocentini et al., 2002); Raven's Coloured Progressive Matrices (Carlesimo et al., 1996); Trail Making Test-Part B (Giovagnoli et al., 1996); (d) Language: Objects and Verbs Naming subtests from the Neuropsychological Examination of Aphasia (Capasso and Miceli, 2001); and (e) Visual-spatial functions: Copy of Drawings and Copy of Drawings with Landmarks (Carlesimo et al., 1996); Copy of Rey's Figure (Carlesimo et al., 2002).

Additional tests were administered to assess executive functioning according to the ability they investigated: Zoo Map test (Wilson et al., 1998; planning and self-monitoring), Stroop test (Barbarotto et al., 1998; response inhibition and self-monitoring), Alternate Phonemic and Category fluency (Cognitive Flexibility/shifting) and Category Fluency (Costa et al., 2014c).

In order to standardize the measurement scales between the different tests, raw scores were transformed into $z$-scores by considering the means and standard deviations of the HC group.

First, a unique $z$-score was computed for each cognitive domain (i.e., episodic memory, attention and short-term memory, executive functions, language and visual-spatial domains) by averaging subjects' $z$-scores on tests belonging to that specific domain.

Following Koven and Collins (2014), to investigate the possible correlation between BDNF levels and specific components of the executive domain (abstract reasoning/planning, self-monitoring/response inhibition, cognitive flexibility, fluency and working memory), individual $z$-scores were computed for each executive component by averaging the subjects' $z$-scores on the relative tests. Thus, an individual score was obtained for abstract reasoning/planning (total accuracy score on the Zoo Map Test; number of categories achieved on the MCST; accuracy score on the Progressive Matrices), Self-monitoring/Response inhibition (Errors made on the Zoo Map Test; errors made and response times on interference condition of the Stroop test), Cognitive Flexibility (perseverative errors committed on the MCST; accuracy score on Alternate Phonemic and Semantic fluency; Trail Making Test Part B-Part A score), Fluency (Phonemic and Semantic fluency), and Working memory (Digit and Corsi span backward). All $z$-scores were considered as absolute values so that higher scores corresponded to better performance. 


\section{Blood Sampling}

Blood samples were collected between 8:00 a.m. and 10:00 a.m., centrifuged at $2000 \times \mathrm{g}$ for $20 \mathrm{~min}$ and stored at $-80^{\circ} \mathrm{C}$ until analysis (Angelucci et al., 2015).

\section{Determination of BDNF Content}

BDNF was detected in sandwich enzyme-linked immunoassay (ELISA; R\&D Systems, USA; cat. $N^{\circ}$ DY248) according to the manufacturer's instructions as previously described (Angelucci et al., 2015). Wells were developed with tetramethylbenzidine and measured at 450/570 $\mathrm{nm}$ and BDNF content was quantified against a standard curve calibrated with known amounts of protein. The detection limit for BDNF was $15 \mathrm{pg} / \mathrm{ml}$. Measurements were performed in duplicate and values are expressed as $\mathrm{ng} / \mathrm{ml}$. Cross-reactivity with other related trophic factors (NGF, NT-3; NT-4; TGF $\beta$, TGF $\alpha$ ) was less than $3 \%$ (Angelucci et al., 2015).

\section{Statistical Analysis}

In order to compare PD patients' and HCs' scores on the five main cognitive domains (episodic memory, attention and short-term memory, executive functions, language, visual-spatial functions), a multivariate analysis of variance (MANOVA) and individual univariate ANOVAS were carried out.

Pearson's $r$ correlations were performed to examine the relationship between BDNF serum levels and $z$-scores obtained by PD patients in the different cognitive domains examined.

The same statistical analysis was used to examine the correlation between BDNF serum levels and PD patients' $z$-scores on the different executive components.

\section{Results}

\section{Comparisons Between PD Patients and Healthy Controls}

The $z$-scores obtained by the experimental subjects are illustrated in Figure 1. The MANOVA showed a significant effect $\left(F_{(5,27)}=9.64 ; p<0.001\right)$. Subsequent univariate analyses showed that PD patients obtained significantly lower $z$-scores than $\mathrm{HC}$ in the cognitive domains of memory, executive functions, attention and visual-spatial abilities $\left(F_{(1,33)}\right.$ range: $17.1-32.5 ; p<0.001$ in all cases). By contrast, in the language domain the between group difference only approached statistical significance $\left(F_{(1,33)}=3.44\right.$; $p=0.073)$.

\section{Correlation Between BDNF Serum Levels and PD Patients' Cognitive Scores}

\section{Analysis Involving the Five Main Cognitive Domains}

Results of Pearson's $r$ correlation analyses showed a significant positive correlation between BDNF serum levels and PD patients' $z$-scores in the executive $(r=0.62 ; p=0.023)$ and attention $(r=0.59 ; p=0.032)$ domains. This indicates that better scores on the above tests were associated with a higher concentration of BDNF. The effects related to analyses involving the remaining three cognitive domains did not reach statistical significance (episodic memory: $r=-0.27 ; p=0.36$; visualspatial domain: $r=0.33$; $p=0.26$; language domain: $r=-0.05$; $p=0.88)$.

\section{Analyses Involving the Different Components of the Executive Domain}

A significant positive correlation was found between BDNF levels and $z$-scores referring to self-monitoring/response inhibition $(r=0.68 ; p=0.011)$ and working memory $(r=0.62 ; p=0.025)$ performance, indicating that higher BDNF levels were associated with better cognitive performance. The remaining analyses showed no significant effects (Planning/Abstraction: $r=0.48$; $p=0.098$; shifting: $r=0.41 ; p=0.17$; Fluency: $r=0.06 ; p=0.85$ ).

\section{Discussion}

This study investigated the association between cognitive functioning and BDNF serum level in PD patients with MCI. For this purpose, we administered an extensive neuropsychological battery to a sample of $\mathrm{PD}$ patients including tests for the assessment of episodic memory, executive functions, attention, language and visual-spatial abilities. The results showed a positive association between BDNF serum levels and performance on neuropsychological tests investigating executive functioning and attention. Moreover, other analyses focusing on the different components of the executive domain showed a

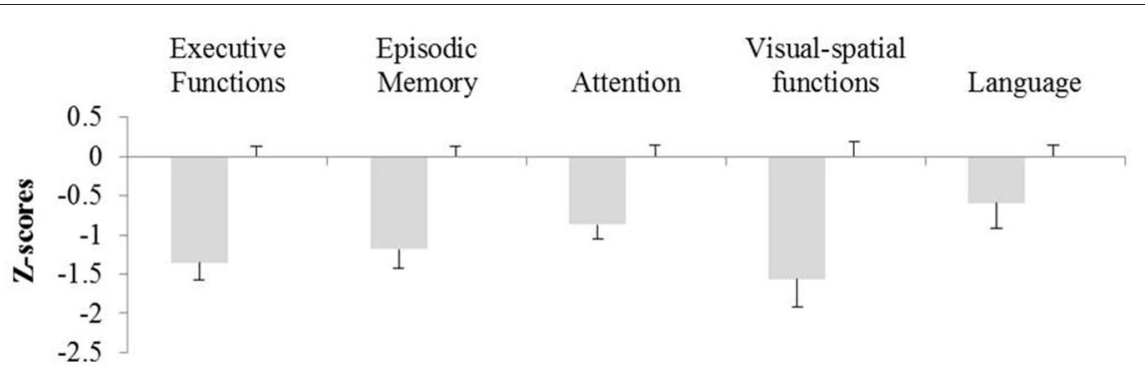

Cognitive Domains

FIGURE 1 | Parkinson's disease (PD) patients' $z$-scores on the different cognitive domains examined. The $x$ axis represents healthy controls (HC) values (averaged). Vertical bars represent standard errors. 
closer association between BDNF levels and working memory and self-monitoring/inhibition.

Our results are congruent with previous data reported in both animal and human studies that documented an association between BDNF-related activity and cognitive functioning (Koven and Collins, 2014; Robbins and Cools, 2014), particularly with data suggesting a specific association with abilities in the executive system domain (Gajewski et al., 2011; Alfimova et al., 2012; Lu et al., 2012; Tükel et al., 2012; Koven and Collins, 2014). In fact, molecular studies reported that the BDNF gene polymorphism (Val66Met) may affect executive functions in healthy subjects (Alfimova et al., 2012) and in patients with psychiatric disturbances (Lu et al., 2012; Tükel et al., 2012). Very interestingly, Koven and Collins (2014), who adopted a design similar to ours, recently documented a significant relationship in healthy subjects between (urinary) BDNF concentration and performance on executive tests. These authors examined a sample of more than 50 healthy young subjects who were administered a neuropsychological test battery investigating different subcomponents of the executive system. Adopting a correlational design, they demonstrated that subjects' performance on tests tapping cognitive flexibility (i.e., Trail Making Test, Design Fluency and Verbal Category Switching) was positively associated with BDNF urinary concentrations. Our results differed from those of Koven and Collins in that we did not find a specific association between BDNF and setshifting (although the relative correlation was in the expected direction). In fact, BDNF serum concentration correlated with the executive scores of working memory, self-monitoring and abstraction/planning. The imperfect congruence between our results and those of Koven and Collins' study is likely due to differences in the recruited samples. Indeed, the participants in Koven and Collins' study were healthy young individuals. Instead, our sample consisted of PD patients with a known cognitive weakness (i.e., MCI with a predominantly dysexecutive and amnestic neuropsychological profile).

BDNF plays a role in the promotion of the survival and function of striatal dopaminergic neurons and in regulating synaptic connectivity (Gómez-Palacio-Schjetnan and Escobar, 2013; He et al., 2013). Other studies have shown that BDNF brain and peripheral levels are decreased in PD patients as compared to HC (Scalzo et al., 2010). Moreover, Gyárfás et al. (2010) demonstrated that treatment with antiparkinsonian drugs may rise BDNF levels. As previously mentioned, PD is characterized by altered functioning of the brain dopamine systems, which involve the nigro-striatal, mesocortical and mesolimbic pathways (Robbins and Cools, 2014). More specifically, dopamine deafferentation primarily involves the nigro-dorsal striatum pathways and dopamine projections to the dorsal prefrontal cortex (Baydyuk and Xu, 2014). In this regard, it has been hypothesised that in the early stages of PD dopamine altered activity is associated with cognitive weakness due to the regional distribution of dopamine receptor dysfunctioning (Cools and D'Esposito, 2011). In fact, dopamine depletion has an early effect on the striatal regions that are rich with D2 receptors, whose phasic activity is important for sustaining cognitive flexibility processes (Camps et al., 1990;
Yeterian and Pandya, 1991; Agid et al., 1993; MacDonald and Monchi, 2011). Only later it involves the dorsal prefrontal cortex where tonic D1 activity sustains the ability to retain stable representations in the face of incoming information (i.e., resistance to interference, self-monitoring; Cohen et al., 2002; Frank, 2005; Costa et al., 2009, 2014b; Cools and D'Esposito, 2011). In fact, weakness of the executive system is a frequent and precocious finding in PD (Dirnberger and Jahanshahi, 2013). Therefore, our finding of a significant correlation between BDNF serum levels and prefrontal-related cognitive performance, although preliminarily, supports the hypothesis that BDNF activity contributes to maintaining normal prefrontal cortex functioning (Savitz et al., 2006; Woo and Lu, 2006; Galloway et al., 2008). In addition, the data presented here, together with the observation that $\mathrm{BDNF}$ is reduced in the brain and in the serum of $\mathrm{PD}$ patients, could suggest that the measurement of BDNF in serum may be used as a biological correlate of cognitive as well as motor functioning. The fact that BDNF levels positively correlate with performance on neuropsychological tests is encouraging. Although we demonstrated in a previous work that a cognitive rehabilitation protocol was able to increase BDNF serum levels and cognitive functions in $\mathrm{PD}$ patients affected by MCI, we did not find a significant correlation between the biological and neuropsychological data (Angelucci et al., 2015). As the number of patients was even smaller (7/8 patients per group) and only one measure of executive functioning was used, we can speculate that the lack of correlation in that study could have been due to both insufficient sample size and low sensitivity of the cognitive measure used to measure executive dysfunction in these patients.

Nonetheless, some limitations should be taken into account in the interpretation of our data. The study is limited by the poor sample size. Furthermore, we are merely describing an association between BDNF serum and cognitive performance and not a causal relationship. PD is now considered a multisystemic neurodegenerative disorder that is characterized by a combination of motor and non-motor symptoms (Stacy, 2011). For a long time the main clinical focus in PD has been on the motor symptoms resulting from degeneration of the substantia nigra and the dopaminergic nigrostriatal pathway, but there is increasing recognition that other brain areas are involved in the manifestation of non motor symptoms (Rana et al., 2015) including the cerebral cortex (Lindenbach and Bishop, 2013), brainstem (Greene, 2014) and peripheral nervous system (Conte et al., 2013). Thus, alterations of BDNF brain and peripheral levels may occur in response to other deficits in these PD associated brain areas. This may limit the possibility to use BDNF as a possible marker of PD cognitive disturbances. Future studies, such as those using PET (Positron Emission Tomography), are needed to establish a direct correlation between dopaminergic denervation and BDNF.

In conclusion, this study shows that BDNF serum levels correlate positively with performance on neuropsychological tests investigating executive functioning and attention. These findings support the idea that this protein may represent a 
possible peripheral marker of cognitive functioning, although this hypothesis needs to be confirmed in larger cohorts of samples and with different methodologies.

\section{Author Contributions}

AC, AP made substantial contributions to the conception and design of the work, and the acquisition, analysis, and interpretation of data for the work; GAC made substantial contributions to the conception and design of the work; SZ

\section{References}

Agid, Y., Ruberg, M., Javoy-Agid, F., Hirsch, E., Raisman-Vozari, R., Vyas, S., et al. (1993). Are dopaminergic neurons selectively vulnerable to Parkinson's disease? Adv. Neurol. 60, 148-164.

Alfimova, M. V., Korovaitseva, G. I., Lezheiko, T. V., and Golimbet, V. E. (2012). Effect of BDNF Val66Met polymorphism on normal variability of executive functions. Bull. Exp. Biol. Med. 152, 606-609. doi: 10.1007/s10517-012$1587-\mathrm{x}$

Alonso-Navarro, H., Jimenez-Jimenez, F. J., Garcia-Martin, E., and Agundez, J. A. (2014). Genomic and pharmacogenomic biomarkers of Parkinson's disease. Curr. Drug Metab. 15, 129-181. doi: 10.2174/1389200215021403271 75404

Angelucci, F., Peppe, A., Carlesimo, G. A., Serafini, F., Zabberoni, S., Barban, F., et al. (2015). A pilot study on the effect of cognitive training on BDNF serum levels in individuals with Parkinson's disease. Front. Hum. Neurosci. 9:130. doi: $10.3389 /$ fnhum.2015.00130

Barbarotto, R., Laiacona, M., Frosio, R., Vecchio, M., Farinato, A., and Capitani, E. (1998). A normative study on visual reaction times and two stroop colour-word tests. Ital. J. Neurol. Sci. 19, 161-670. doi: 10.1007/bf00831566

Baydyuk, M., and Xu, B. (2014). BDNF signaling and survival of striatal neurons. Front. Cell. Neurosci. 8:254. doi: 10.3389/fncel.2014.00254

Beck, A. T., Ward, C. H., Mendelson, M., Mock, M., and Erbaugh, J. (1961). An inventory for measuring depression. Arch. Gen. Psychiatry 4, 561-571. doi: 10. 1001/archpsyc.1961.01710120031004

Białecka, M., Kurzawski, M., Roszmann, A., Robowski, P., Sitek, E. J., Honczarenko, K., et al. (2014). BDNF G196A (Val66Met) polymorphism associated with cognitive impairment in Parkinson's disease. Neurosci. Lett. 561, 86-90. doi: 10.1016/j.neulet.2013.12.051

Camps, M., Kelly, P. H., and Palacios, J. M. (1990). Autoradiographic localization of dopamine D1 and D2 receptors in the brain of several mammalian species. J. Neural Transm. Gen. Sect. 80, 105-127. doi: 10.1007/bf01257077

Capasso, R., and Miceli, G. (2001). Esame Neuropsicologico Dell'Afasia. Milano: Springer Verlag.

Carlesimo, G. A., Buccione, I., Fadda, L., Graceffa, A., Mauri, M., Lorusso, S., et al. (2002). Standardizzazione di due test di memoria per uso clinico: breve racconto e figura di Rey. Nuova Riv. di Neurol. 12, 1-13.

Carlesimo, G. A., Caltagirone, C., and Gainotti, G. (1996). The mental deterioration battery: normative data, diagnostic reliability and qualitative analyses of cognitive impairment. the group for the standardization of the mental deterioration battery. Eur. Neurol. 36, 378-384. doi: 10.1159/0001 17297

Cohen, J. D., Braver, T. S., and Brown, J. W. (2002). Computational perspectives on dopamine function in prefrontal cortex. Curr. Opin. Neurobiol. 12, 223-229. doi: $10.1016 /$ s0959-4388(02)00314-8

Conte, A., Khan, N., Defazio, G., Rothwell, J. C., and Berardelli, A. (2013). Pathophysiology of somatosensory abnormalities in parkinson disease. Nat. Rev. Neurol. 9, 687-697. doi: 10.1038/nrneurol.2013.224

Cools, R. (2006). Dopaminergic modulation of cognitive function-implications for L-DOPA treatment in Parkinson's disease. Neurosci. Biobehav. Rev. 30, 1-23. doi: 10.1016/j.neubiorev.2005.03.024

Cools, R., and D'Esposito, M. (2011). Inverted-U-shaped dopamine actions on human working memory and cognitive control. Biol. Psychiatry 69, e113-e125. doi: 10.1016/j.biopsych.2011.03.028 and FS made substantial contributions to the the acquisition of data for the work; CC made substantial contributions to the conception and design of the work; FA made substantial contributions to the conception of the work, and to the acquisition, analysis, and interpretation of data for the work; all drafted the work and revised it critically for important intellectual content; gave final approval of the version to be published; and agreed to be accountable for all aspects of the work in ensuring that questions related to the accuracy or integrity of any part of the work were appropriately investigated and resolved.

Costa, A., Monaco, M., Zabberoni, S., Peppe, A., Perri, R., Fadda, L., et al. (2014a). Free and cued recall memory in Parkinson's disease associated with amnestic mild cognitive impairment. PLoS One 9:e86233. doi: 10.1371/journal.pone. 0086233

Costa, A., Peppe, A., Mazzù, I., Longarzo, M., Caltagirone, C., and Carlesimo, G. A. (2014b). Dopamine treatment and cognitive functioning in individuals with Parkinson's disease: the "cognitive flexibility" hypothesis seems to work. Behav. Neurol. 2014:260896. doi: 10.1155/2014/260896

Costa, A., Bagoj, E., Monaco, M., Zabberoni, S., De Rosa, S., Papantonio, A. M., et al. (2014c). Standardization and normative data obtained in the Italian population for a new verbal fluency instrument, the phonemic/semantic alternate fluency test. Neurol. Sci. 35, 365-372. doi: 10.1007/s10072-013-1520-8

Costa, A., Peppe, A., Dell'Agnello, G., Caltagirone, C., and Carlesimo, G. A. (2009). Dopamine and cognitive functioning in de novo subjects with Parkinson's disease: effects of pramipexole and pergolide on working memory. Neuropsychologia 47, 1374-1381. doi: 10.1016/j.neuropsychologia.2009. 01.039

Dai, L., Wang, D., Meng, H., Zhang, K., Fu, L., Wu, Y., et al. (2013). Association between the BDNF G196A and C270T polymorphisms and Parkinson's disease: a meta-analysis. Int. J. Neurosci. 123, 675-683. doi: 10.3109/00207454.2013. 798784

Dirnberger, G., and Jahanshahi, M. J. (2013). Executive dysfunction in Parkinson's disease: a review. J. Neuropsychol. 7, 193-224. doi: 10.1111/jnp.12028

Dubois, B., Burn, D., Goetz, C., Aarsland, D., Brown, R. G., Broe, G. A., et al. (2007). Diagnostic procedures for Parkinson's disease dementia: recommendations from the movement disorder society task force. Mov. Disord. 22, 2314-2324. doi: 10.1002/mds.21844

Folstein, M. F., Folstein, S. E., and McHugh, P. R. (1975). "Mini-mental state". A practical method for grading the cognitive state of patients for the clinician. J. Psychiatr. Res. 12, 189-198. doi: 10.1016/0022-3956(75)90026-6

Foltynie, T., Lewis, S. G., Goldberg, T. E., Blackwell, A. D., Kolachana, B. S., Weinberger, D. R., et al. (2005). The BDNF Val66Met polymorphism has a gender specific influence on planning ability in Parkinson's disease. J. Neurol. 252, 833-838. doi: 10.1007/s00415-005-0756-5

Frank, M. (2005). Dynamic dopamine modulation in the basal ganglia: a neurocomputational account of cognitive deficits in medicated and non-medicated parkinsonism. J. Cogn. Neurosci. 17, 51-72. doi: 10 1162/0898929052880093

Gajewski, P. D., Hengstler, J. G., Golka, K., Falkenstein, M., and Beste, C. (2011). The Met-allele of the BDNF Val66Met polymorphism enhances task switching in elderly. Neurobiol. Aging 32, 2327.e7-2327.e19. doi: 10.1016/j. neurobiolaging.2011.06.010

Galloway, E. M., Woo, N. H., and Lu, B. (2008). Persistent neural activity in the prefrontal cortex: a mechanism by which bdnf regulates working memory? Prog. Brain Res. 169, 251-266. doi: 10.1016/s0079-6123(07)00015-5

Giovagnoli, A. R., Del Pesce, M., Mascheroni, S., Simoncelli, M., Laiacona, M., and Capitani, E. (1996). Trail making test: normative values from 287 normal adults controls. Ital. J. Neurol. Sci. 17, 305-309. doi: 10.1007/bf01997792

Gómez-Palacio-Schjetnan, A., and Escobar, M. L. (2013). Neurotrophins and synaptic plasticity. Curr. Top. Behav. Neurosci. 15, 117-136. doi: 10. 1007/7854_2012_231

Gorski, J. A., Balogh, S. A., Wehner, J. M., and Jones, K. R. (2003). Learning deficits in forebrain-restricted brain-derived neurotrophic factor mutant mice. Neuroscience 121, 341-354. doi: 10.1016/s0306-4522(03)00426-3 
Gottmann, K., Mittmann, T., and Lessmann, V. (2009). BDNF signaling in the formation, maturation and plasticity of glutamatergic and GABAergic synapses. Exp. Brain Res. 199, 203-234. doi: 10.1007/s00221-009-1994-Z

Greene, J. G. (2014). Causes and consequences of degeneration of the dorsal motor nucleus of the vagus nerve in Parkinson's disease. Antioxid. Redox. Signal. 21, 649-667. doi: 10.1089/ars.2014.5859

Guerini, F. R., Beghi, E., Riboldazzi, G., Zangaglia, R., Pianezzola, C., Bono, G., et al. (2009). BDNF Val66Met polymorphism is associated with cognitive impairment in italian patients with Parkinson's disease. Eur. J. Neurol. 16, 1240-1245. doi: 10.1111/j.1468-1331.2009.02706.x

Guillin, O., Griffon, N., Bezard, E., Leriche, L., Diaz, J., Gross, C., et al. (2003). Brain-derived neurotrophic factor controls dopamine D3 receptor expression: therapeutic implications in Parkinson's disease. Eur. J. Pharmacol. 480, 89-95. doi: 10.1016/j.ejphar.2003.08.096

Gyárfás, T., Knuuttila, J., Lindholm, P., Rantamäki, T., and Castrén, E. (2010). Regulation of brain-derived neurotrophic factor (BDNF) and cerebral dopamine neurotrophic factor (CDNF) by anti-parkinsonian drug therapy in vivo. Cell. Mol. Neurobiol. 30, 361-368. doi: 10.1007/s10571-009-9458-3

He, Y. Y., Zhang, X. Y., Yung, W. H., Zhu, J. N., and Wang, J. J. (2013). Role of BDNF in central motor structures and motor diseases. Mol. Neurobiol. 48, 783-793. doi: 10.1007/s12035-013-8466-y

Heldt, S. A., Stanek, L., Chhatwal, J. P., and Ressler, K. J. (2007). Hippocampusspecific deletion of BDNF in adult mice impairs spatial memory and extinction of aversive memories. Mol. Psychiatry 12, 656-670. doi: 10.1038/sj.mp. 4001957

Howells, D. W., Porritt, M. J., Wong, J. Y., Batchelor, P. E., Kalnins, R., Hughes, A. J., et al. (2000). Reduced BDNF mRNA expression in the Parkinson's disease substantia nigra. Exp. Neurol. 166, 127-135. doi: 10.1006/exnr. 2000.7483

Hughes, A. J., Daniel, S. E., Kilford, L., and Lees, A. J. (1992). Accuracy of clinical diagnosis of idiopathic Parkinson's disease: a clinicopathological study of 100 cases. J. Neurol. Neurosurg. Psychiatry 55, 181-184. doi: 10.1136/jnnp. 55.3 .181

Hyman, C., Hofer, M., Barde, Y. A., Juhasz, M., Yancopoulos, G. D., Squinto, S. P., et al. (1991). BDNF is a neurotrophic factor for dopaminergic neurons of the substantia nigra. Nature 350, 230-232. doi: 10.1038/350230a0

Jahanshahi, M., Jones, C. R., Zijlmans, J., Katzenschlager, R., Lee, L., Quinn, N., et al. (2010). Dopaminergic modulation of striato-frontal connectivity during motor timing in Parkinson's disease. Brain 133, 727-745. doi: 10. 1093/brain/awq012

Jiménez-Jiménez, F. J., Alonso-Navarro, H., García-Martín, E., and Agúndez, J. A. (2014). Cerebrospinal fluid biochemical studies in patients with Parkinson's disease: toward a potential search for biomarkers for this disease. Front. Cell. Neurosci. 8:369. doi: 10.3389/fncel.2014.00369

Karamohamed, S., Latourelle, J. C., Racette, B. A., Perlmutter, J. S., Wooten, G. F., Lew, M., et al. (2005). BDNF genetic variants are associated with onset age of familial parkinson disease: gene PD Study. Neurology 65, 1823-1825. doi: 10. 1212/01.wnl.0000187075.81589.fd

Koponen, E., Võikar, V., Riekki, R., Saarelainen, T., Rauramaa, T., Rauvala, H., et al. (2004). Transgenic mice overexpressing the full-length neurotrophin receptor trkB exhibit increased activation of the trkB-PLCgamma pathway, reduced anxiety and facilitated learning. Mol. Cell. Neurosci. 26, 166-181. doi: 10.1016/j.mcn.2004.01.006

Koven, N. S., and Collins, L. R. (2014). Urinary brain-derived neurotrophic factor as a biomarker of executive functioning. Neuropsychobiology 69, 227-234. doi: 10.1159/000362242

Lawton, M. P., and Brody, E. M. (1969). Assessment of older people; selfmaintaining and instrumental activity of daily living. Gerontologist 9, 179-186. doi: 10.1093/geront/9.3_part_1.179

Leal, G., Afonso, P. M., Salazar, I. L., and Duarte, C. B. (2014). Regulation of hippocampal synaptic plasticity by BDNF. Brain Res. 1621, 82-101. doi: 10 . 1016/j.brainres.2014.10.019

Leentjens, A. F., Dujardin, K., Marsh, L., Martinez-Martin, P., Richard, I. H., Starkstein, S. E., et al. (2008). Apathy and anhedonia rating scales in Parkinson's disease: critique and recommendations. Mov. Disord. 23, 2004-2014. doi: 10. 1002/mds.22229

Leverenz, J. B., Watson, G. S., Shofer, J., Zabetian, C. P., Zhang, J., and Montine, T. J. (2011). Cerebrospinal fluid biomarkers and cognitive performance in non-demented patients with Parkinson's disease. Parkinsonism Relat. Disord. 17, 61-64. doi: 10.1016/j.parkreldis.2010.10.003

Li, M., Dai, F. R., Du, X. P., Yang, Q. D., Zhang, X., and Chen, Y. (2012). Infusion of BDNF into the nucleus accumbens of aged rats improves cognition and structural synaptic plasticity through PI3K-ILK-Akt signaling. Behav. Brain Res. 231, 146-153. doi: 10.1016/j.bbr.2012.03.010

Lindenbach, D., and Bishop, C. (2013). Critical involvement of the motor cortex in the pathophysiology and treatment of Parkinson's disease. Neurosci. Biobehav. Rev. 37, 2737-2750. doi: 10.1016/j.neubiorev.2013.09.008

Litvan, I., Goldman, J. G., Tröster, A. I., Schmand, B. A., Weintraub, D., Petersen, R. C., et al. (2012). Diagnostic criteria for mild cognitive impairment in Parkinson's disease: movement disorder society Task force guidelines. Mov. Disord. 27, 349-356. doi: 10.1002/mds.24893

Lu, W., Zhang, C., Yi, Z., Li, Z., Wu, Z., and Fang, Y. (2012). Association between BDNF Val66Met polymorphism and cognitive performance in antipsychoticnaïve patients with schizophrenia. J. Mol. Neurosci. 47, 505-510. doi: 10. 1007/s12031-012-9750-4

MacDonald, P. A., and Monchi, O. (2011). Differential effects of dopaminergic therapies on dorsal and ventral striatum in Parkinson's disease: implications for cognitive function. Parkinsons Dis. 2011:572743. doi: 10.4061/2011/ 572743

Marin, R. S., Biedrzycki, R. C., and Firinciogullari, S. (1991). Reliability and validity of the apathy evaluation scale. Psychiatry Res. 38, 143-162. doi: 10.1016/01651781(91)90040-v

Monaco, M., Costa, A., Caltagirone, C., and Carlesimo, G. A. (2013). Forward and backward span for verbal and visuo-spatial data: standardization and normative data from an italian adult population. Neurol. Sci. 34, 749-754. doi: 10.1007/s10072-012-1130-x

Monteggia, L. M., Barrot, M., Powell, C. M., Berton, O., Galanis, V., Gemelli, T., et al. (2004). Essential role of brain-derived neurotrophic factor in adult hippocampal function. Proc. Natl. Acad. Sci. U S A 101, 10827-10832. doi: 10. 1073/pnas.0402141101

Murer, M. G., Yan, Q., and Raisman-Vozari, R. (2001). Brain-derived neurotrophic factor in the control human brain and in Alzheimer's disease and Parkinson's disease. Prog. Neurobiol. 63, 71-124. doi: 10.1016/s03010082(00)00014-9

Nocentini, U., Di Vincenzo, S., Panella, M., Pasqualetti, P., and Caltagirone, C. (2002). La valutazione delle funzioni esecutive nella pratica neuropsicologica; dal modified card sorting test al modified card sorting test-roma version. Dati di standardizzazione. Nuova Riv. di Neurol. 12, 13-24.

Pålhagen, S., Qi, H., Mårtensson, B., Wålinder, J., Granérus, A. K., and Svenningsson, P. (2010). Monoamines, BDNF, IL-6 and corticosterone in CSF in patients with Parkinson's disease and major depression. J. Neurol. 257, 524-532. doi: 10.1007/s00415-009-5353-6

Rana, A. Q., Ahmed, U. S., Chaudry, Z. M., and Vasan, S. (2015). Parkinson's disease: a review of non-motor symptoms. Expert. Rev. Neurother. 15, 549-562. doi: 10.1586/14737175.2015.1038244

Robbins, T. W., and Cools, R. (2014). Cognitive deficits in Parkinson's disease: a cognitive neuroscience perspective. Mov. Disord. 29, 597-607. doi: 10. $1002 / \mathrm{mds} .25853$

Salehi, Z., and Mashayekhi, F. (2009). Brain-derived neurotrophic factor concentrations in the cerebrospinal fluid of patients with Parkinson's disease. J. Clin. Neurosci. 16, 90-93. doi: 10.1016/j.jocn.2008.03.010

Savitz, J., Solms, M., and Ramesar, R. (2006). The molecular genetics of cognition: dopamine, COMT and BDNF. Genes Brain Behav. 5, 311-328. doi: 10.1111/j. 1601-183x.2005.00163.x

Scalzo, P., Kümmer, A., Bretas, T. L., Cardoso, F., and Teixeira, A. L. (2010). Serum levels of brain-derived neurotrophic factor correlate with motor impairment in Parkinson's disease. J. Neurol. 257, 540-545. doi: 10.1007/s00415-0095357-2

Stacy, M. (2011). Nonmotor symptoms in Parkinson's disease. Int. J. Neurosci. 121(Suppl. 2), 9-17. doi: 10.3109/00207454.2011.620196

Svetel, M., Pekmezovic, T., Markovic, V., Novaković, I., Dobričić, V., Djuric, G., et al. (2013). No association between brain-derived neurotrophic factor G196A polymorphism and clinical features of parkinson's disease. Eur. Neurol. 70, 257-262. doi: 10.1159/000352033

Tükel, R., Gürvit, H., Ozata, B., Oztürk, N., Ertekin, B. A., Ertekin, E., et al. (2012). Brain-derived neurotrophic factor gene Val66Met polymorphism and 
cognitive function in obsessive compulsive disorder. Am. J. Med. Genet. B Neuropsychiatr. Genet. 159, 850-858. doi: 10.1002/ajmg.b.32092

Visser, M., Verbaan, D., van Rooden, S., Marinus, J., van Hilten, J., and Stiggelbout, A. (2009). A longitudinal evaluation of health-related quality of life of patients with Parkinson's disease. Value Health 12, 392-396. doi: 10.1111/j.1524-4733. 2008.00430.x

Wilson, B. A., Evans, J. J., Emslie, H., Alderman, N., and Burgess, P. (1998). The development of an ecologically valid test for assessing patients with a dysexecutive syndrome. Neuropsychol. Rehab. 8, 213-228. doi: 10. 1080/713755570

Woo, N. H., and Lu, B. (2006). Regulation of cortical interneurons by neurotrophins: from development to cognitive disorders. Neuroscientist 12, 43-56. doi: $10.1177 / 1073858405284360$

Yeterian, E. H., and Pandya, D. N. (1991). Prefrontostriatal connections in relation to cortical architectonic organization in rhesus monkeys. J. Comp. Neurol. 312, 43-67. doi: 10.1002/cne.903120105
Ziebell, M., Khalid, U., Klein, A. B., Aznar, S., Thomsen, G., Jensen, P., et al. (2012). Striatal dopamine transporter binding correlates with serum BDNF levels in patients with striatal dopaminergic neurodegeneration. Neurobiol. Aging 33, 428.e1-428.e5. doi: 10.1016/j.neurobiolaging.2010.11.010

Conflict of Interest Statement: The authors declare that the research was conducted in the absence of any commercial or financial relationships that could be construed as a potential conflict of interest.

Copyright (๑) 2015 Costa, Peppe, Carlesimo, Zabberoni, Scalici, Caltagirone and Angelucci. This is an open-access article distributed under the terms of the Creative Commons Attribution License (CC BY). The use, distribution and reproduction in other forums is permitted, provided the original author(s) or licensor are credited and that the original publication in this journal is cited, in accordance with accepted academic practice. No use, distribution or reproduction is permitted which does not comply with these terms. 